\title{
Temperature Controlled Exhaust Heat Thermoelectric Generation
}

\author{
Francisco P. Brito, Jorge Martins, L.M. Goncalves and Rui Sousa \\ Universidade do Minho
}

Copyright $\odot 2012$ SAE International

doi: $\underline{10.4271 / 2012-01-1214}$

\begin{abstract}
The amount of energy wasted through the exhaust of an Internal Combustion Engine (ICE) vehicle is roughly the same as the mechanical power output of the engine. The high temperature of these gases (up to $1000^{\circ} \mathrm{C}$ ) makes them intrinsically apt for energy recovery. The gains in efficiency for the vehicle could be relevant, even if a small percentage of this waste energy could be regenerated into electric power and used to charge the battery pack of a Hybrid or Extended Range Electric Vehicle, or prevent the actuation of a conventional vehicle's alternator.
\end{abstract}

This may be achieved by the use of thermodynamic cycles, such as Stirling engines or Organic Rankine Cycles (ORC). However, these systems are difficult to downsize to the power levels typical of light vehicle exhaust systems and are usually bulky. The direct conversion of thermal energy into electricity, using Thermoelectric Generators (TEG) is very attractive in terms of minimal complexity. However, current commercial thermoelectric modules based on Seebeck effect are temperature limited, so they are unable to be in direct contact with the exhaust gases. A way to downgrade the temperature levels without significantly reducing the regeneration potential is to interpose Heat Pipes (HP) between the exhaust gas and the Seebeck modules in a controlled way. This control of maximum permissible temperature at the modules is achieved by regulating the pressure of phase change of the service fluid of the HP. In this way the system will be failsafe against overheating and will be able to operate efficiently under both low and high thermal loads. Such is the case of the range extender unit being developed by the team, which has a low $(15 \mathrm{~kW})$ and a high $(40 \mathrm{~kW})$ power mode of operation.
Various designs concepts were evaluated by simulation, design and test. Although efficiencies were still moderate, it was possible to demonstrate the potential of this system for optimizing the output of commercially available temperature limited TEGs.

\section{INTRODUCTION}

\subsection{MOTIVATION}

Lately, a global trend to cut emissions and increase energy efficiency is being pursued by the transportation industry [1] in order to comply with the evermore stringent current and future national and international agreements and policies on GHG emissions, such as the Climate and Energy Package issued by the European Commission [2] and the Corporate Average Fuel Efficiency (CAFE) in the USA [ $\underline{3}$ ]. Although a significant effort has been done to date in order to reduce energy waste in Internal Combustion Engines, there is still a big portion, around two thirds of the total energy released by combustion that is wasted through the tailpipe and the engine cooling systems in approximately equal parts $[\underline{4}, \underline{5}]$.

Energy waste may be reduced by the use of strategies that improve energy efficiency such as turbo-charging and overexpansion, but this improvement is still limited. A step further in energy efficiency would be to recycle exhaust heat in some way. Some works have proposed the use of a heat exchanger at the exhaust pipe to recover the heat and redirect it to the system. It can then be used, for instance, to heat up the engine oil more quickly in order to improve energy efficiency during cold starts []]. The gradual electrification of the vehicle is making the electric recovery of this thermal energy more attractive. This would be especially useful in Hybrid Electric Vehicles (HEV), range extended electric vehicles (EREV) and vehicles with only mild electrification such as those with Start-Stop and related technologies. Even 
conventional vehicles would benefit from this recovery being able to reduce alternator electricity production power.

Both Organic Rankine Cycle (ORC) turbines [7] and thermoelectric Generators (TEG) based on the Seebeck effect $[\underline{8}, \underline{9}, \underline{10}]$ have been tested in heavy duty vehicles for electric exhaust heat recovery during the last decades. Nevertheless, all three have limitations. ORCs have the highest recovery potential but they are still not viable for low duty engines [11], although some effort in low power applications has been made recently [12]. On the other hand, the efficiency of TEG systems has been improving significantly in the last few years due to the application of novel materials technology $[13,14]$ but currently available systems still display a lower efficiency than ORCs. Nonetheless, for low power applications they currently stand as the only practical option since they are intrinsically scalable [11].

The first tests of thermoelectric generation applied to automotive waste heat recovery started some decades ago with works such as the one made by Neild [15], and other works made with modified cars/engines such as a Porsche 944 [16], a 14 litre Cummins Turbo-diesel engine truck [17] a GM Sierra Pickup Truck [1] $]$ and other, more recent works $[\underline{19}, \underline{20}, \underline{21}, \underline{22}]$. However, the power recovered was hardly enough to meet the electric demands of the various electrical accessories. Nonetheless, if the recovery potential of the cooling, lubrication and exhaust systems is combined, it should be possible to recover a significantly higher amount of energy [23, 24]. Major OEMs like Honda [25] and BMW are testing this technology. The latter is making plans to commercialize in the near future a car with TEGs generating up to $1 \mathrm{~kW}$ (currently $200 \mathrm{~W}$ ), with the aim of $5 \%$ fuel savings [26].

Works such as [27] point out to the possibility of having an efficiency of heat recovery (to electricity) using advanced thermoelectric generators of $5 \%$, which would translate into an extra $6 \%$ (1\% from coolant, $5 \%$ from exhaust) of available (electric) energy in a hybrid car. Consequently, an engine with 33\% efficiency could earn 3\% extra mechanical power, translated into $5 \%$ in fuel savings.

A major limitation of current commercially available TEGs is that they cannot safely withstand the temperature levels found in typical exhaust systems, which easily exceed $500^{\circ} \mathrm{C}$ under high loads. This fact enforces the downgrading of the operating temperature of the modules. Of course, this means reducing the energy conversion potential according to the second law of thermodynamics, but for now it is an inevitable limitation that hopefully will be mitigated over time. In fact, the current temperature limitation of TEGs such as those made with Bismuth Telluride alloys $\left(320^{\circ} \mathrm{C}\right.$ to $350^{\circ} \mathrm{C}$ limit) has more to do with the frailty of the solderings rather than with the melting point of the alloy itself. For well known fixed operating conditions, it would be possible to thermally dimension a system so as to work at a specified operating temperature, but this passive system would have poor performance below nominal loads and would risk seizure for excessive loads. Some systems had to incorporate gates and actuators in order to by-pass part or all of the exhaust flux in order to avoid system meltdown. This translates into added cost and complexity.

A solution for passively avoid TEG overheating at high thermal load while simultaneously providing efficient operation even at low loads seems to lie in a system that would be capable of maintaining the desired operating temperature irrespective of the regime by automatically adjusting the heat flux reaching the TEGs. This could be achieved through the use of heat pipes with adjustable boiling temperature, such as the Variable Conductance Heat Pipes (VCHP). One advantage of this system is that is displays a very low thermal resistance. Therefore, taking into account that this application has to be temperature limited, a solution like this one allows maximizing the thermal efficiency for those conditions.

The group started exploring the potential of exhaust energy recovery within the scope of a supermileage contest for hybrid vehicles, with a preliminary assessment of systems with and without heat pipe assist [28]. Another paper detailed some of the results obtained with simplified proof-of-concept installations [29]. A more recent work dealt with the theoretical modelling of a TEG-heat pipe system [30]. The present work is being made in the scope of the development of a Range Extender for an electric vehicle. This particular Range Extender, based on the concept of over-expansion (Miller cycle, in which the authors have expertise [31]), is to be used under two different regimes. The default regime is used for maximizing efficiency and displays a low thermal load (around $15 \mathrm{~kW}$ ). There will also be a regime that engages whenever extra power is needed, producing around $40 \mathrm{~kW}$ of mechanical power. A system such as the one described above is needed to allow an efficient electric recovery in both regimes. In the present work results concerning conveniently instrumented TEGs with heat pipe assist are presented in order to assess the potential of heat pipe-based systems for thermoelectric generation of engine waste exhaust heat. A method for safely controlling the maximum temperature achieved by TEGs in exhaust systems is assessed with several proof-of-concept prototypes. As the modules are somewhat expensive and the engine is expected to run at light load for most of the time, the aim of the project is to design the system for these light load conditions, therefore requiring a safety strategy against module overheating.

\subsection{THERMOELECTRIC GENERATORS (TEGs)}

Thermoelectric generators (TEG) are based on the Seebeck effect. A temperature difference between the junctions of two 
different materials generates a voltage. Depending on the electrical resistance of these materials, an electric current will flow when the circuit is closed, and electrical power will be available. The overall performance of the TEG, quantified with the figure-of-merit (ZT), depends on three main parameters: Seebeck coefficient $(\alpha)$, electrical resistivity $(\rho)$ and thermal conductivity $(\lambda)$ at a given temperature $(T)$ :

$$
\mathrm{ZT}=\frac{\alpha^{2}}{\rho \cdot \lambda} \mathrm{T}
$$

The efficiency of a TEG module ( $\eta$ ) will be dependent on ZT and the temperatures along its surfaces, cold and hot sides, respectively $\mathrm{TC}$ and $\mathrm{TH}$ :

$$
\eta=\left(\frac{\mathrm{T}_{\mathrm{H}}-\mathrm{T}_{\mathrm{C}}}{\mathrm{T}_{\mathrm{H}}}\right)\left(\frac{\sqrt{1+\mathrm{ZT}}-1}{\sqrt{1+\mathrm{ZT}}+\frac{\mathrm{T}_{\mathrm{C}}}{\mathrm{T}_{\mathrm{H}}}}\right)
$$

A candidate for a good thermoelectric material must have a high Seebeck coefficient (a large voltage is generated for a given temperature difference), a small resistivity (a large current could be drawn from the generator) and a small thermal conductivity (the temperature difference between the hot and cold faces of the TEG may be maximized, increasing the efficiency). The ZT can also be calculated at a given temperature $\mathrm{T}$ for a thermoelectric module (instead of a single material), considering the voltage generated for each degree of temperature difference $\mathrm{V}$ [VK-1], the electrical resistance $\mathrm{Ri}[\Omega]$ and the thermal conductance K [WK-1]

$$
\mathrm{ZT}=\frac{\mathrm{V}^{2}}{\mathrm{Ri} . \mathrm{K}} \mathrm{T}
$$

The commercially available thermoelectric modules, made of Bismuth Telluride and Antimony Telluride have top efficiency in the range between 0 to $200{ }^{\circ} \mathrm{C}$ but ZT decreases for temperature above $200{ }^{\circ} \mathrm{C}$, thus reducing efficiency. Moreover, mechanical stability of these modules often limits operation temperature to a maximum around $250{ }^{\circ} \mathrm{C}$.

The thermoelectric modules produce a voltage (VO) that is proportional to the temperature difference between the hot and the cold plates of each module:

$$
V_{O}=n \alpha\left(T_{H}-T_{C}\right)
$$

where $\mathrm{n}$ is the number of thermoelectric modules. The mean Seebeck coefficient is considered, since the Seebeck coefficient is not constant over the working temperature range. All modules are connected electrically in series, thus the total voltage generated (VO) and the total internal resistance (Ri) are the sum of the voltage produced by each module and the internal resistance of each module, respectively.
The maximum power output of the modules for a load (PO) occurs when the load resistance (RL) equals the sum of internal resistance of the modules ( $\mathrm{Ri}$ is the electrical resistance of each module and $\mathrm{n} . \mathrm{Ri}$ is the total resistance, when the modules are connected in series). A mean value is used since the resistance is not constant over the working temperature range.

$$
P_{O}=\frac{\left(n \alpha\left(T_{H}-T_{C}\right)\right)^{2}}{4 n R_{i}}
$$

Previous work [30] from the authors demonstrated that these modules could be used for energy generation in automobile applications. TEGs can be electrically modulated as a voltage source (dependent from the temperature at both sides) with an internal electric resistance (Ri). The almost linear behaviour of the module simplifies the implementation of simple Maximum-Power-Point-Tracking (MPPT) electronic circuit to use the available power in an efficient manner, charging the vehicle batteries at full available power, as presented before [무] .

\subsection{HEAT PIPE WORKING PRINCIPLE}
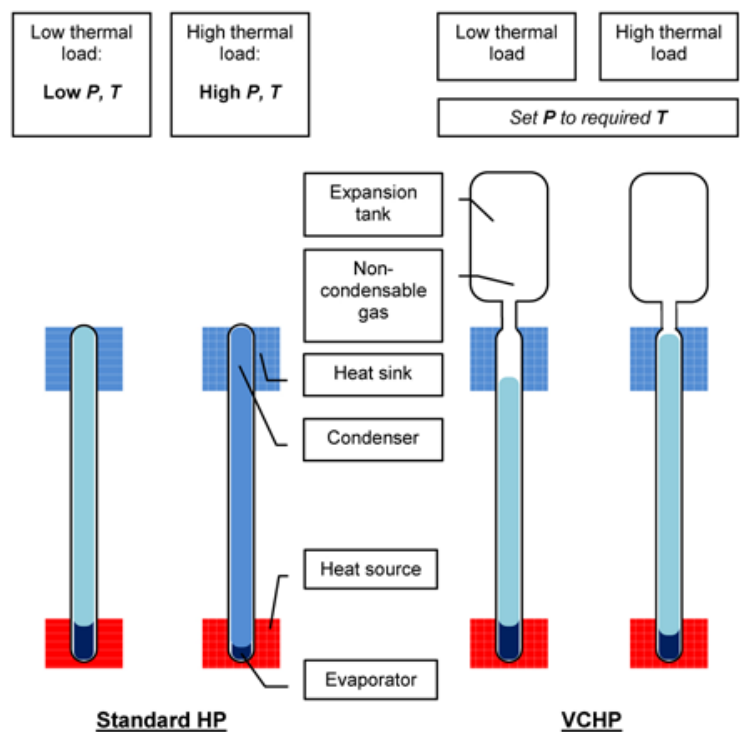

Figure 1. Comparison of Standard and Variable Conductance Heat Pipes under variable thermal load

Although very simple in their working principle, HPs (heat pipes) are of relatively recent use in industry [32]. A basic Heat Pipe consists of a sealed upright pipe containing a small portion of phase-changing fluid (see Figure 1 - left). The remainder of the inner volume of the pipe is occupied either by the thermal fluid vapour or by a mix of vapour and nonphase-changing gas (such as air). Due to gravity, the fluid rests at the bottom of the pipe (the heat source region, or evaporator of the HP), where it will be heated and boiled under the action of the heat crossing the pipe walls through 


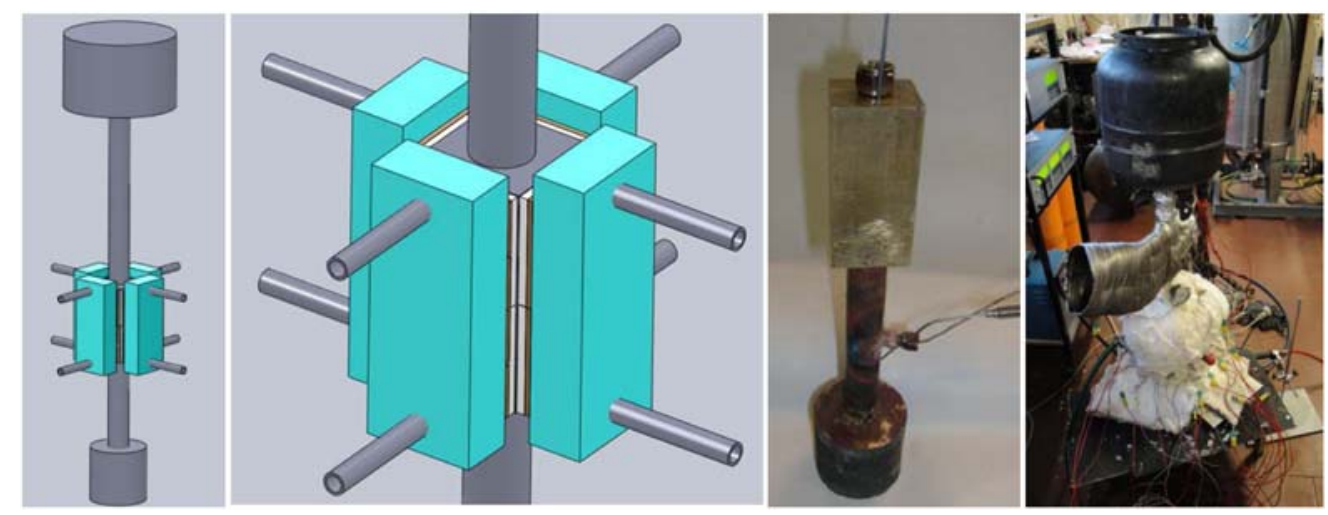

Figure 2. Basic Proof-of-concept model used in the current work

conduction. The vaporized fluid will eventually condense at the upper part of the pipe wall releasing its heat to the heat sink. Once condensed, the liquid droplets will fall back to the bottom of the pipe, completing the cycle and being ready to vaporize and condense over and over again.

A Heat Pipe will only start transferring heat from the hot source to the heat sink once the boiling temperature of the fluid has been achieved. This boiling temperature is not a static value but depends on the actual pressure of the fluid inside the HP (the pressure also changes during operation).

\subsection{VARIABLE CONDUCTANCE HEAT PIPES (VCHPs)}

One way of controlling the phase changing temperature of a fluid would be to control its pressure. If the pressure could be kept constant at a specified value, then a certain HP operating temperature could be regulated. The use of an expansion tank attached to the top of the HP will enable this outcome (Figure 1 - right). Therefore, pressure would not build up during operation as it would in a standard HP and the boiling would not be hampered by an excessive increase of pressure. Such a system is called a Variable Conductance Heat Pipe (VCHP) and has been used in the current work.

The comparison between the response of standard HPs and VCHPs for low and high thermal loads is outlined in Figure 1 (top). It is expected that with this system the HP will be able to work at a specified temperature. This will be made by adjusting the HP pressure to control the boiling temperature (the operating temperature of the VCHP) regulating it to the maximum allowable TEG temperature, thus optimizing the heat transfer rate of the system while protecting the system from over-heating.

\section{EXPERIMENTAL PROCEDURE}

\subsection{BASIC PROOF-OF-CONCEPT MODEL}

In order to test the concept of TEG heat management through heat pipes a basic experimental model was built (See Figure 2). This model is in no way optimized for direct application in real vehicles but has been built in order to provide some insight into the thermal performance potential of heat pipebased thermal management of a thermoelectric generator. A $22 \mathrm{~mm}$ diameter copper pipe serves as the HP body that links the HP evaporator and condenser. It is soldered at the lower end to a wide diameter solid brass base with a hole in the continuity of the pipe. This block serves as the HP evaporator on which the heat source substituting exhaust heat (a blowtorch flame) is directed (see sketch in Figure 3). The upper end of the copper pipe is connected to another brass block with square section and drilled in continuity with the pipe hole. The inner surface of the block acts as the HP condenser and there are 8 thermoelectric modules attached to the exterior faces of the block. On the outer face of these modules 4 aluminium flat ducts are attached to act as the heat sink of the modules. Inside these ducts cool water is forced to flow at a specified rate.

The top of the HP condenser block is connected to a large cylinder vessel $(20 \mathrm{~L})$. The purpose of this vessel is to maintain the HP pressure at the specified value, therefore setting the required temperature of phase change of the thermal fluid (water). This pressure is pre-regulated by injecting air into the system with an air compressor. 


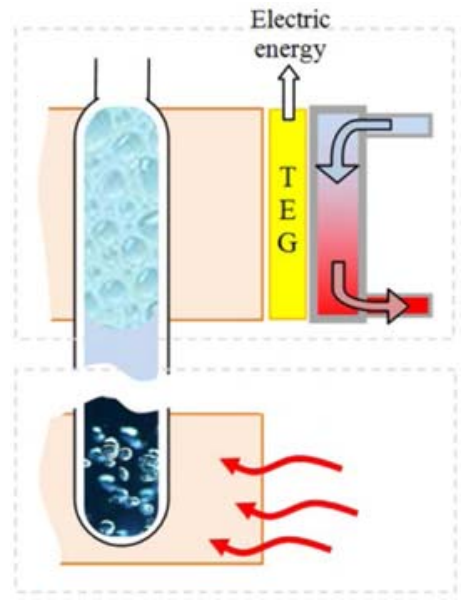

Figure 3. Outline of the operating principle of the basic proof-of-concept model

Thermocouples were placed at various locations to measure the temperature and determine heat fluxes throughout the prototype. Care was taken to minimize the effect of contact thermal resistance, using thermal grease. It was also possible to assess the maximum potential for the supplied heat by looking at the temperatures of the pipe connecting the HP to the large vessel. If some of these temperatures were below the boiling temperature for the set pressure and others were at the boiling temperature, we could be sure that the condenser was working fully and there was no vapour passing to the vessel. That was the setting for steady-state at maximum heat flux.

The aluminium flat ducts were connected in series and the water flow was set at a level where the temperature difference would be enough for proper heat calculation, but was high enough for keeping the modules at the lowest possible average temperature. A connection is series was preferred to parallel as the water velocity would be 4 times higher (in each duct) for the same total temperature difference, therefore enhancing the convective heat transfer coefficients.

The bismuth-telluride thermoelectric modules used in the generator (TEC1-12708 from Thermoelectric Supplier) were connected electrically in series. These modules, with dimensions of $40 \times 40 \times 3.6 \mathrm{~mm} 3$, can steadily support temperatures up to $240^{\circ} \mathrm{C}$.

In half of the modules, the open circuit voltage (generator without load) was measured. In the other half, output voltage was measured with a known Ohm resistive load connected to the output. With this setup, considering the open circuit voltage and voltage at a given load, internal resistance of the module and maximum available power (obtained with maximum power point tracking hardware at a matched output load) was calculated, considering a linear resistive internal impedance on the generator. Efficiency was calculated considering the maximum available electrical power (at a matched load) and the thermal power crossing the modules.

\subsection{IMPROVED PROOF-OF-CONCEPT MODEL}

A second proof-of-concept model has been built in order to further assess the potential of heat pipe based thermal management of thermoelectric generators for exhaust heat recovery. This system, shown in Figure 4a, is modular, as it is divided into three identical sections with 4 thermoelectric generators each ( 2 at each face). These three system modules are exposed sequentially to the hot gases, so that if the thermal load is small, it will be mainly absorbed by the first evaporator facing the hot gases. This cascade operation is intended to avoid an excessive thermal dilution in low thermal load events that would likely occur with a non modular approach. The vaporization side of the system was over-designed so the heat transfer limitation would occur at the condensation end of the system, where the highest thermal resistance occurs. With this aim, several long externally finned copper tubes were used for the vaporization side (Figure 4b).

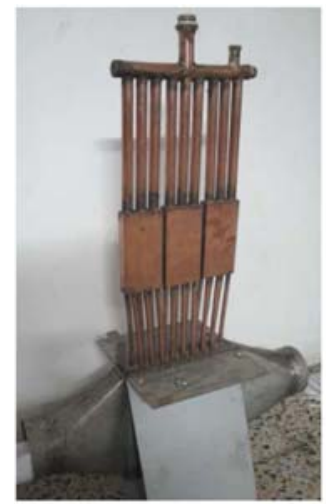

(a)

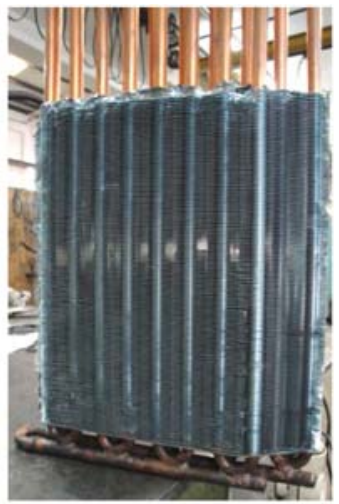

(b)
Figure 4. (a) image of the model installed at the hot gases duct; (b) detail of the evaporator.

The finned evaporator, with 7 fins per centimetre, was immersed in a duct flow of hot gases. The flame of either one or two propane gas blowtorches was directed into the duct and a blower at the outlet of the duct was used to force the flow across the duct. Also it is possible to restrict the flow of hot gases to the system through a guillotine-type shutter.

As seen in Figure 4b, the evaporator has 18 finned pipes that are all interconnected at the bottom, with $8 \mathrm{~mm}$ outer diameter and $0.5 \mathrm{~mm}$ of thickness. Each 6 pipes have been grouped to serve each one of the 3 condenser blocks. These blocks, shown in Figure 5, are $20 \mathrm{~mm}$ thickness solid copper blocks with an area that fits two vertically aligned thermoelectric modules (RS Amidata ref. 6937116 with dimensions $62 \times 62$ 


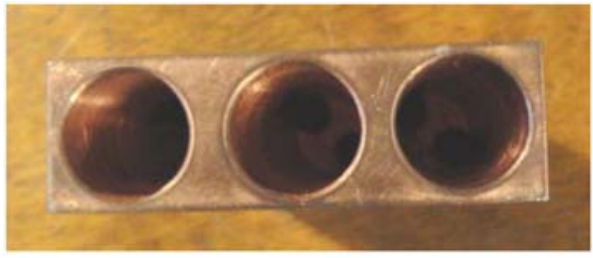

(a)

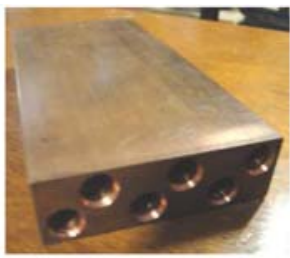

(b)

Figure 5. (a) upper view and (b) lower view of the condenser blocks.

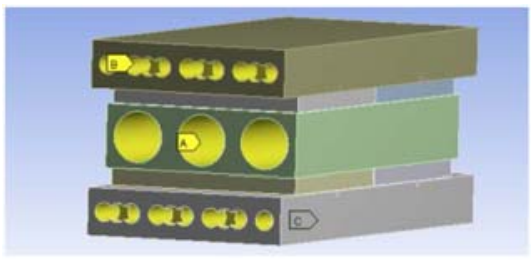

(a)

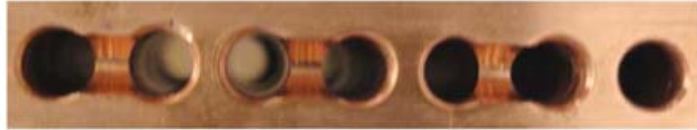

(b)

Figure 6. (a)Outline of the mounting of the condenser blocks, thermoelectric generators and cooling ducts; (b) detail of the cooling ducts before interconnection of the channels in series.

$\times 5.3 \mathrm{~mm} 3$ ) on each face. These blocks are drilled with two different diameter wholes, as shown in Figure 5. From the bottom of the condenser block, where the 6 heat pipes have been soldered, up to two thirds of the block height, there are six $8 \mathrm{~mm}$ holes. These are intercepted by three $16 \mathrm{~mm}$ holes drilled from the top of the block down to a depth of two thirds of the total block height. The condensation of the working fluid is expected to occur on these inner surfaces.

Water ducts for TEG cooling have been attached to the outer faces of the thermoelectric modules as shown in Figure 6a. These were also made with solid copper blocks $(15 \mathrm{~mm}$ thick) drilled with seven $6 \mathrm{~mm}$ holes within which the water flows in order to capture the heat flowing from the modules, keeping their outer face as cool as possible (see Figure 6b). To maximize the convective heat transfer the contiguous channels were connected in zig-zag in a series configuration so that water speed and turbulence can be maximized.

Above each condenser block three pipes were soldered to the $16 \mathrm{~mm}$ top holes, as seen previously in Figure 4a. These pipes connect to a collector that gathers all the pipes coming from the three condenser blocks and links them to the expansion vessel (for pressure stabilization) located at the top of the system. The three system modules are only interconnected at the bottom collector (below the evaporator) and at the collector located above the condenser. This has been made with the purpose of having a modular system with cascade operation while still having just one common expansion vessel and having an even liquid distribution across all evaporator pipes.
One risk of the inclusion of the expansion vessel into the system is that in some cases some vapour might migrate to that region and stay away from the condenser. To detect this phenomenon several thermocouples were placed above the condenser up to the expansion vessel region in order to detect the presence of hot vapour. Surrounding the pipe that connects the system to the expansion vessel a closed cup with water circulation was installed to enforce the condensation of the vapour located in this region (seeFigure 7a). The level of the liquid at the evaporator was checked with a vertical glass tube connected to the collector below the evaporator (see Figure 7b).

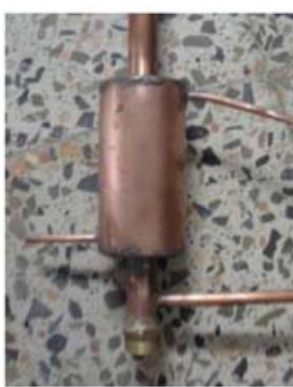

(a)

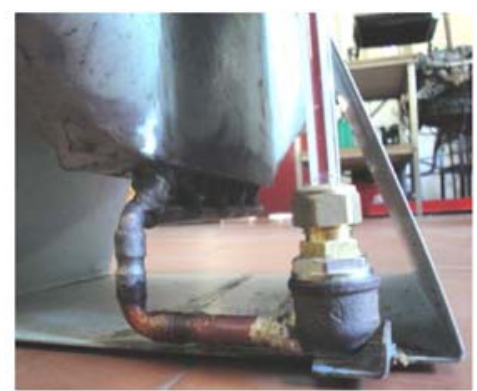

(b)
Figure 7. (a) Detail of the auxiliary cooling system to avoid vapour escape to the expansion vessel; (b) detail of the glass tube that allows checking the level of liquid at the evaporator. 


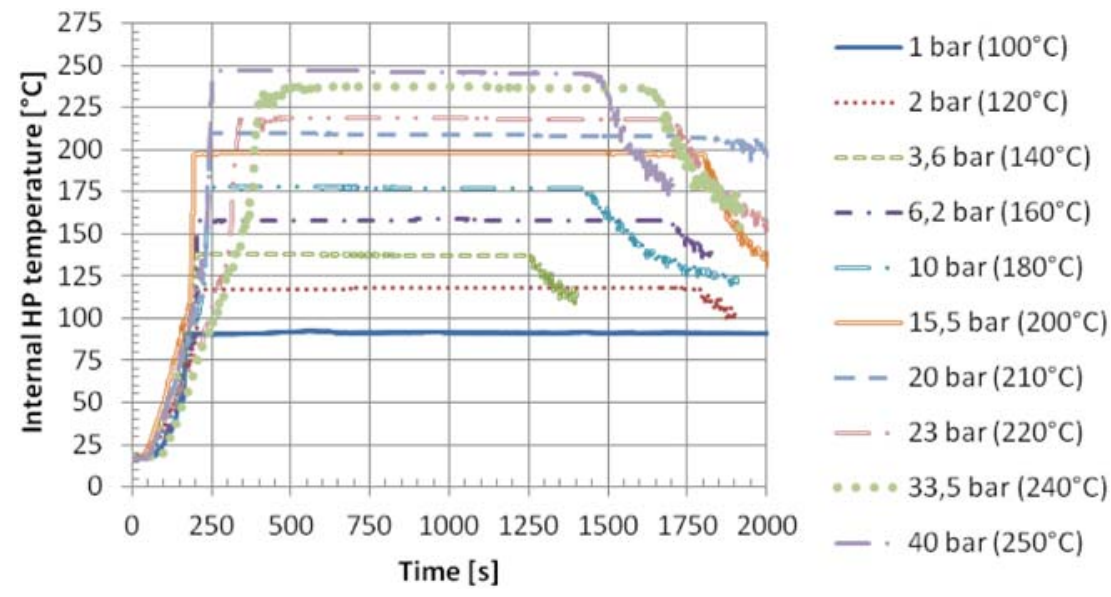

Figure 8. Internal heat pipe temperature over time as a function of the inner HP pressure setting.

This model allows the test of a range of operating pressures that will provide operating temperatures up to the temperature limit of the modules (around $250^{\circ} \mathrm{C}$ ), but for this work the only pressures tested were 1 bar (atmospheric pressure, providing an operating temperature of $100^{\circ} \mathrm{C}$ ) and 6.2 bar (providing an operating temperature around $160^{\circ} \mathrm{C}$ ). Naturally, higher global efficiencies will be obtained as temperature increases, but we were not been able to go beyond 6.2 bar as the glass pipe and its fittings would not allow it.

For both proof-of-concept models the power of the heat source has been decreased whenever the temperature sensors that are above the condenser detect a temperature that signals the presence of vapour in this region. This has been made to avoid the migration of vapour to the region of the expansion vessel signalling that the condensing power limit of the system has been exceeded. Therefore, with this regulation of the heat input it is possible to understand the limits of the system in terms of thermal power input. Based on the thermodynamic modelling carried out by the authors, in both models the power output of the system is clearly limited at the condenser and not at the evaporator, especially in the case of the improved model. This means that the evaporator of the improved system could be used for a much higher amount of thermoelectric modules.

It was found that the series configuration of the modules associated with a densely finned evaporator might cause the heat exchange to concentrate only at the first module instead of spreading to the whole system even with high thermal loads. In some tests all the water boiled at this module with the remaining modules staying inactive. This is due to the unbalance in the evaporator/condenser power output that causes the vaporization rate to be higher than the condensation rate. As said before, this over-sizing of the evaporator was made in order to more clearly identify the condenser limits.

\section{RESULTS AND DISCUSSION}

\subsection{BASIC PROOF-OF-CONCEPT MODEL}

The basic model was tested for a broad range of inner pressures. Each pressure setting (regulated beforehand by injecting compressed air) yields a specific HP operating temperature that corresponds to the water boiling point at that specific pressure. Since the expansion vessel prevents any significant pressure changes during the tests, the operating temperature is expected to be constant. This can be seen in Figure 8, where the tests with pressures in the range between 1 bar and 40 bar yielded constant operating temperatures between $100^{\circ} \mathrm{C}$ and $250^{\circ} \mathrm{C}$.

Figure 9 Shows the temperatures recorded during the tests performed with internal pressures of 2 bar and 33.5 bar. It can be seen that once the system achieved its operating temperature (around $120^{\circ} \mathrm{C}$ and $240^{\circ} \mathrm{C}$, respectively) this temperature (line named "HP") was kept unchanged until the time that the heat source was switched off (around $1700 \mathrm{~s}$ and $1600 \mathrm{~s}$, respectively). The temperature of the evaporator base (line named "base") follows closely the HP temperature and never rises to dangerous levels despite being in direct contact with the heat source.

Temperatures $\mathrm{T} 1$ thru $\mathrm{T} 4$ were measured along the pipe between the condenser and the expansion vessel. The rise of these temperatures to values close to the HP temperature signals the presence of vapour phase above the condenser. Particularly, if temperatures $\mathrm{T} 1$ and $\mathrm{T} 2$ rise to values close to the HP temperature it means that the vapour is accessing all the condenser. If temperatures $\mathrm{T} 3$ and $\mathrm{T} 4$ also rise too much this denotes that some of the vapour is starting to enter the expansion vessel, away from the condenser, meaning that there is no sufficient condensing power relatively to evaporative power. This happened during the 2 bar test (Figure 9a) and therefore the heat source power was lowered 


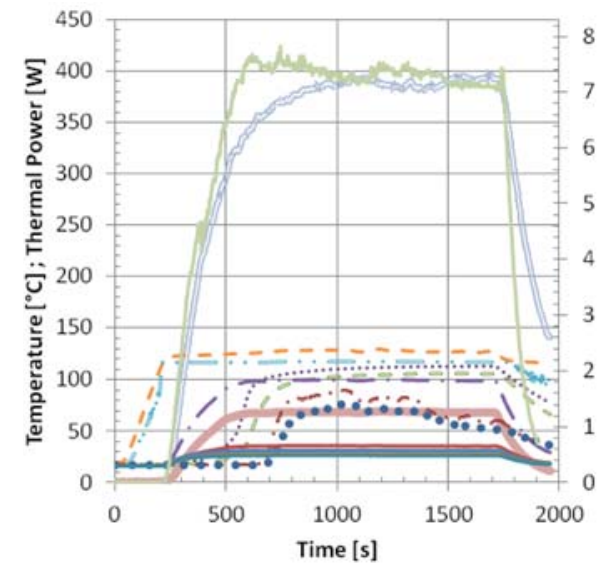

(a)

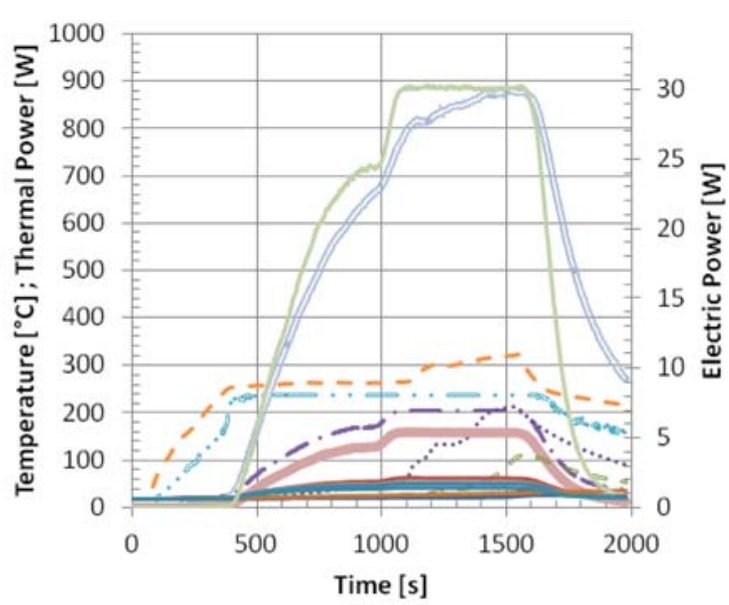

(b)

Figure 9. Temperature results for pressures and cooling flows of (a) $2 \mathrm{bar}, 50,7 \mathrm{~L} / \mathrm{h}$ and (b) $33.5 \mathrm{bar}, 48.7 \mathrm{~L} / \mathrm{h}$. Initial water content was $20 \mathrm{ml}$.

when the elapsed test time was around $1000 \mathrm{~s}$. As it can be seen, Temperatures T3 and T4 decreased as a consequence. What is interesting to note is that the thermal power and the electric power did not decrease significantly despite the reduction of the heat source power. This denotes that the system power output was already saturated before the decrease of the heat source power and so the subsequent decrease of the power output did not affect negatively the performance of the system.

When analyzing the temperatures corresponding to the 33.5 bar test (Figure 9b) it can be seen that, up to $1000 \mathrm{~s}$ of elapsed time, temperatures $\mathrm{T} 1$ and $\mathrm{T} 2$ were not getting close to the HP temperature. This meant that the high pressure air inside the system was preventing the vapour from accessing the whole height of the condenser. Therefore, the heat source power was increased by that time (a second blowtorch was put into operation). As a consequence, there was a sharp rise in the thermal and electric power output of the HP, with temperatures $\mathrm{T} 1$ and $\mathrm{T} 2$ rising. However, this rise in heat source power may have been too intense, because $\mathrm{T} 3$ and $\mathrm{T} 4$ rised sharply and particularly the evaporator ("base" temperature) also started to rise around $1100 \mathrm{~s}$. This means that all the liquid evaporated (because the rate of evaporation was much higher than the rate of condensation) and therefore the temperature limitation normally provided by the system was lost. Maybe a way of preventing this phenomenon to occur will be to increase the condensation power limit of the system (by increasing condenser surface).

The results of thermal power crossing the TEG modules is presented in Figure 10a for the whole range of operating temperatures. These results can be compared against the electric power generated by the 8 TEG modules, presented in Figure $10 \mathrm{~b}$ along with the tension at the modules and the efficiency. This efficiency represents the fraction of the power crossing the modules that has been effectively converted into electrical power.

The maximum electric power figures (around $35 \mathrm{~W}$ ) and efficiencies (around 3\%) obtained are rather modest, but in line with other research results in the area. This has to do with the fact that thermoelectrics are still rather inefficient, especially at low temperatures, and that the system tested, being just a simplified proof-of-concept, is non-optimized. Also, only 8 mass-market modules were used. Nevertheless, the heat transfer method studied seems to have a good potential for temperature control and is able to retrieve more than $800 \mathrm{~W}$ of thermal power from the heat source. The concept of using heat pipes for heat transfer and temperature control seems to have a good potential for this kind of applications and therefore was further explored with an improved model.

\subsection{IMPROVED PROOF-OF-CONCEPT MODEL}

The first results, shown in Figure 11, refer to three tests performed at a pressure of $1 \mathrm{bar}$, with one blowtorch working and for three different duct shutter apertures $(1 / 4,1 / 2$ and fully open, respectively). As intended, the thermal resistance of condensation is very small in all tests because the difference between the HP temperature and the condenser wall is very small, around $1.5^{\circ} \mathrm{C}$. The main differences between the three tests were the time elapsed until approaching steady-state operation (shorter for wider shutter apertures) and also slight differences in gas outlet temperature and power. A reason for the power not increasing significantly with increasing shutter aperture is that the same heat source power is available in all three cases. The only things that change are the gaseous mixture speed due to the variation of the amount of ambient air aspirated. 

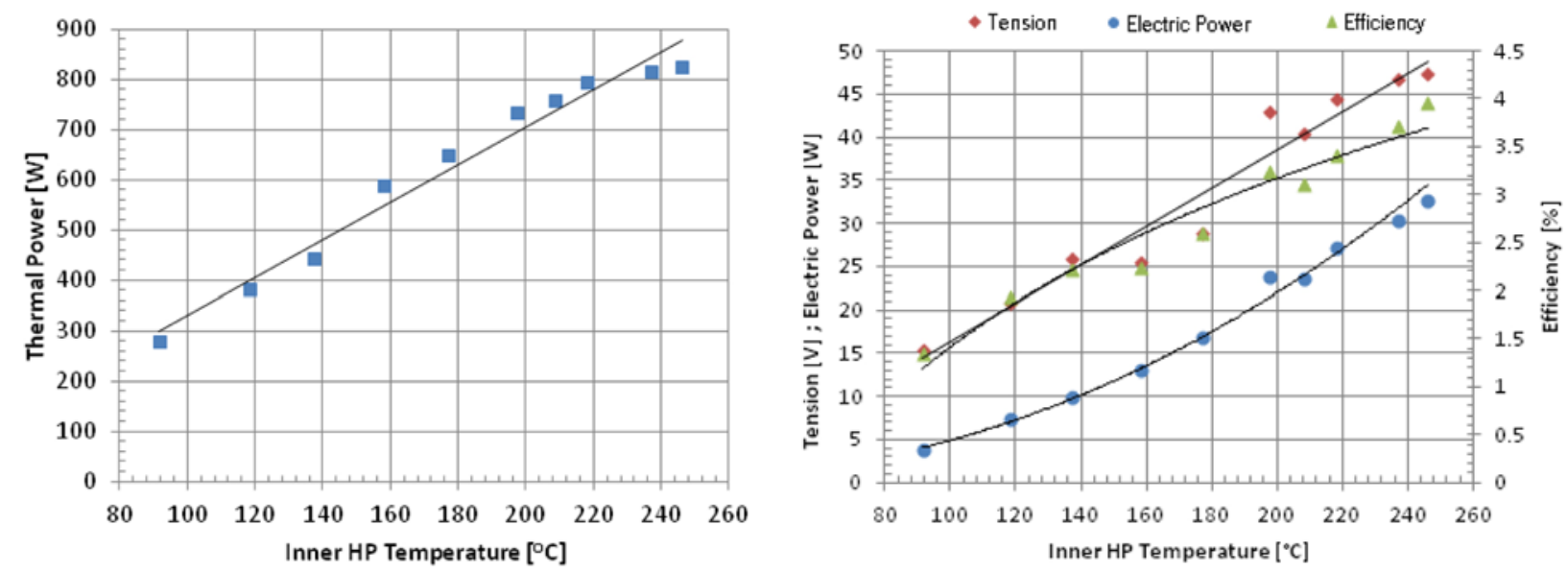

Figure 10. (a) Thermal power crossing the HP as a function of inner HP temperature; (b) tension, electric power and efficiency of thermal to electric conversion.
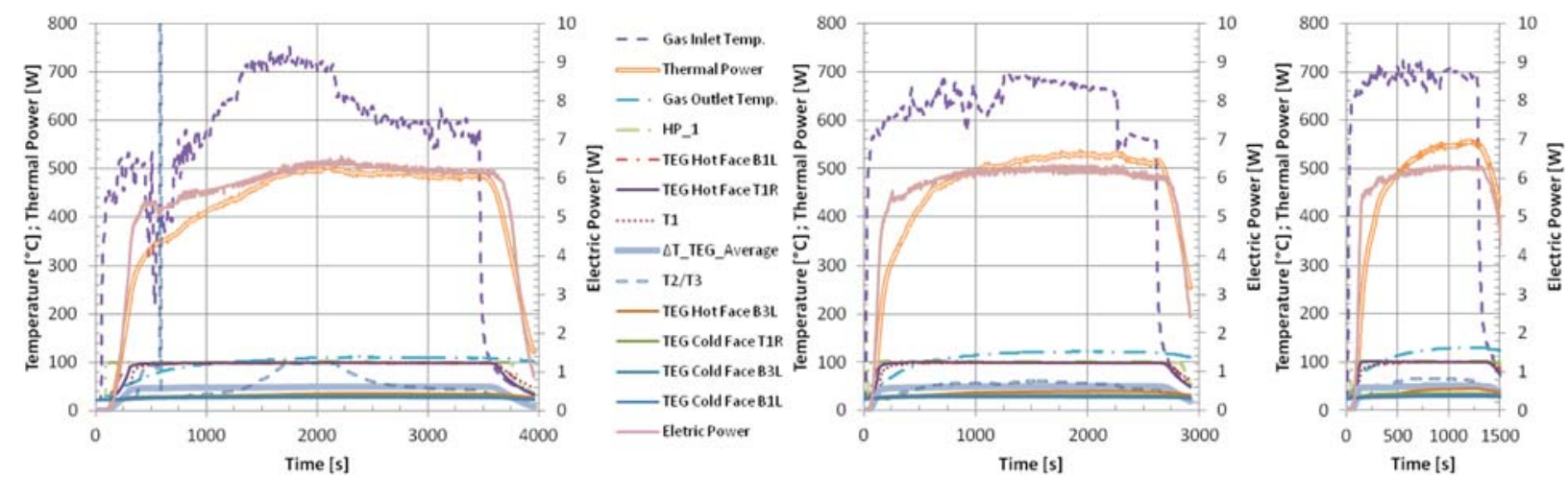

Figure 11. Temperature results with guillotine shutter (a) $1 / 4$ open, (b) $1 / 2$ open and (c) fully open. Cooling flow around $50 \mathrm{~L} / \mathrm{h}$, initial water content $83 \mathrm{ml}$.

In the first test the temperature near the expansion vessel (named "T2/T3") increased up to the HP temperature denoting the existence of vapour high above the condenser. To avoid this behaviour, the heat source power was reduced (note the decrease of the gas inlet temperature after $2200 \mathrm{~s}$ in Figure 11a).

It is important to point out that the first module facing the hot gases (module 1) was responsible for nearly all the electric power output. The module located in the middle (module 2) produced a maximum power which was around $1 / 10$ of that produced by the former, while the electric power produced by the last module facing the gases (module 3) was negligible. Thermally this can be partially observed in the graphs for modules 1 and 3 by observing the hot face temperatures for module 1 (TEG Hot face T1R and B1L, referring to two different thermoelectric generator units) and 3 (TEG Hot face B3L). Unfortunately, it was not possible to measure any face temperatures for module 2. While the hot face temperatures of module 1 are roughly at $\mathrm{HP}$ temperature $\left(100^{\circ} \mathrm{C}\right)$, for module 3 this temperature is below $35^{\circ} \mathrm{C}$, meaning it is barely active. This behaviour illustrates that an excessive unbalance between the evaporative and condensing power might be deleterious for HP operation. This behaviour might be avoided by reducing the fin density to avoid excessive heat transfer to the first module (module 1) facing the hot gases. Another option might be to slightly alter the series configuration (one after another facing the hot gases) of the three modules in some way that would still avoid excessive heat dilution at low loads. The efficiency at steady state is around $0.80 \%$ for all three tests (electric power divided by thermal power), which is low but it is significantly higher than that of the previous model for similar operating conditions.

Figure 12 displays the results for tests with two blowtorches and two different inner pressures. The first two were made at a pressure of 1 bar and shutter apertures of 1/10 (Figure 12a) and totally open shutter (Figure 12b), while the latter one (Figure 12c) was done at 6.2 bar and with the shutter totally open, having been the only test made under this pressure. It can be seen that the heat source power has been reduced at 

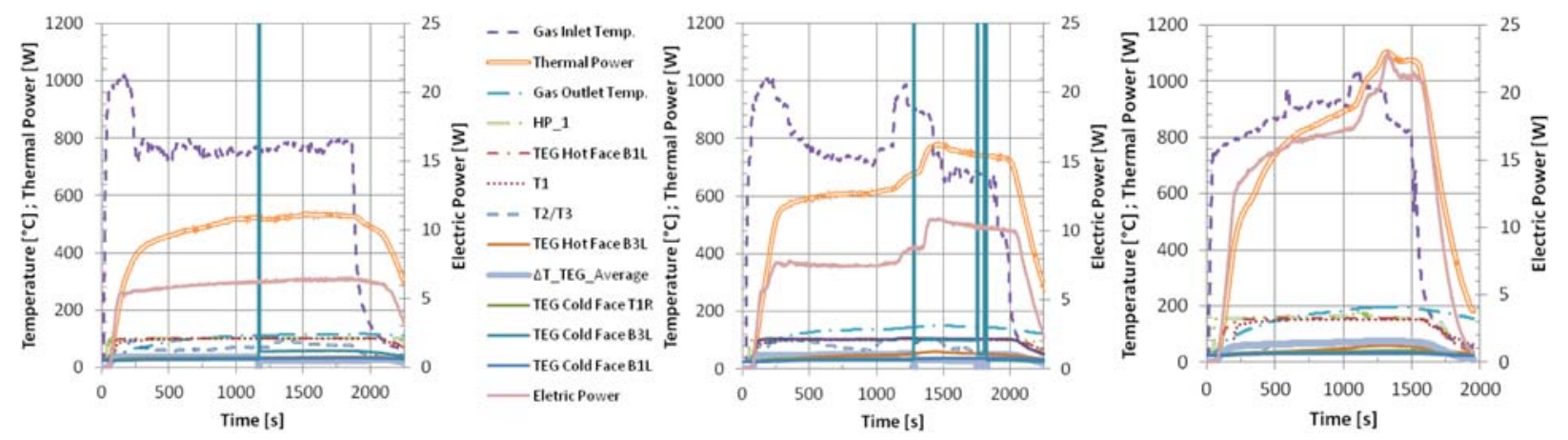

Figure 12. Temperature results for 1 bar pressure with guillotine shutter (a) 1/10 open and (b) wide open; (c) 6.2 bar with guillotine shutter totally open. Cooling flow around $50 \mathrm{~L} / \mathrm{h}$, initial water content $83 \mathrm{ml}$. Two blowtorches used.

some points (denoted by the variation of the gas inlet temperature) in order to keep down the temperature near the expansion vessel (T2/T3) and thus prevent the vapour to rise up to the expansion vessel and away from the condenser. Curiously, for the high pressure ( 6.3 bar) test this temperature never rose significantly. This means that at high pressures this problem is less likely to occur and the heat source power can be high. No pressure higher than 6.2 bar was tested as the glass pipe (shown in Figure $7 \mathrm{~b}$ ) and its fittings would not allow it.

For the two last tests (Figure 12b, ) some electric power generation was observed at module 2 (not shown). The sharp increase of the electric power observed around $1300 \mathrm{~s}$ of elapsed time (Figure 12b) coincided with the increase of power generated by this module. The same happened in the high pressure test around $1200 \mathrm{~s}$ of elapsed time (see Figure $\underline{12 \mathrm{c}}$ ), which recorded a maximum power output of $1150 \mathrm{~W}$ and an electric output of $17.5 \mathrm{~W}$. The efficiencies for these tests were respectively $0.9 \%, 1 \%$ and $1.3 \%$, always higher than the values recorded with the previous proof-of-concept model.

\section{CONCLUSIONS}

In the present work two different proof-of-concept models were tested to assess the potential of using a thermoelectric generator with heat transfer and temperature control performed by heat pipes for automotive exhaust heat recovery with modules based on the Seebeck effect. The heat pipes were used as a means of efficiently transferring the heat from the hot exhaust gases to the TEGs at a temperature level that does not damage the TEGs, which are temperature limited.

A basic prototype was assessed for a wide range of operating temperatures up to $250^{\circ} \mathrm{C}$. It was possible to control the operating temperature of the system by using variable Conductance Heat Pipes incorporating an expansion vessel and regulating the inner pressure. This philosophy seems to be suitable for limiting the operating temperature of the system and thus protect the system against over-heating, while maintaining a good level of thermal power crossing the system. Nevertheless, care should be taken in order to level the evaporator and condenser thermal power output capacities in order to avoid evaporator dry-out. For this system the maximum electric power using 8 modules was around $35 \mathrm{~W}$ with efficiencies up to $3 \%$. These figures are rather modest, although the system is small and is only a non-optimized proof-of-concept prototype.

A second, improved model was tested for a number of cases. The thermal resistances of the system were minimized, with a difference of only $1.5{ }^{\circ} \mathrm{C}$ between the inner HP temperature and the condenser walls. This system is modular with three different sections exposed sequentially in series to the hot gases. Although small, the efficiency of the improved model was always higher than that of the basic model. For low operating pressures/temperatures the heat transfer occurred mainly at the first module and there was need to decrease the power input to avoid excessive evaporation (dry-out). This was due to the unbalance between evaporative and condensing power. Fortunately, at a higher operating pressure/temperature $(6.5 \mathrm{bar})$ this problem disappeared (the air pressure prevented the migration of vapour towards the expansion vessel, isolated from the condenser) and the model did not seem to be limitative for power input, with more modules being active.

These proof-of-concept prototypes have illustrated the potential of temperature controlled thermoelectric generators for automotive applications based on Seebeck modules and heat pipes. Such working philosophy allows the use of temperature limited mass market modules and is suitable for automotive systems with variable thermal load, like the range extender for electric vehicles that is being developed by the team. Further developments in Seebeck module materials with higher figure-of-merit / efficiency and higher operating temperature limit should further increase the potential of this philosophy for exhaust heat thermoelectric regeneration. 


\section{REFERENCES}

1. Jost, K. "Upfront (Editorial): Green Innovations", Automotive Engineering International, 118-3, p. 4. 2010

2. European Commission, EU Climate and Energy Package, 2010, available at http://ec.europa.eu/clima/documentation/ package/docs/climate package en.pdf, (accessed April 25th, 2011);

3. Environmental Protection Agency (EPA), Department of Transportation (DOT), National Highway Traffic Safety Administration (NHTSA). Light-Duty Vehicle Greenhouse Gas Emission Standards and Corporate Average Fuel Economy Standards -Final Rule. Federal Register, Rules and Regulations, Vol. 75, No. 88, May 7, 2010, available at http:// www.nhtsa.gov/staticfiles/rulemaking/pdf/cafe/CAFEGHG MY 2012-2016_Final Rule FR.pdf (accessed April 25th, 2011);

4. Martins, J., "Motores de Combustão Interna", 3rd edition, Publindustria, Porto, Portugal, 2011

5. Heywood, J., Internal Combustion Engine Fundamentals, McGraw Hill, 1988.

6. Will, F. and Boretti, A., "A New Method to Warm Up Lubricating Oil to Improve the Fuel Efficiency During Cold Start," SAE Int. J. Engines 4(1):175-187, 2011, doi: 10.4271/2011-01-0318.

7. Hung, T. C., T. Y. Shai, T. Y., Wang, S. K. "A review of organic rankine cycles (ORCs) for the recovery of low-grade waste heat", Energy, Elsevier, 22-7, pp. 661-667, 1997

8. Birkholz, U., Grob, Stohrer, U. and Voss, K., "Conversion of Waste Exhaust Heat in Automobile using FeSi2

Thermoelements". Proc. 7th International Conference on Thermoelectric Energy Conversion. 1988, Arlington, USA, pp. 124-128, 1988

9. Bass, J. C., Elsner, N. B. and Leavitt, F. A. "Performance of the $1 \mathrm{~kW}$ Thermoelectric Generator for Diesel Engines" International Conference on Thermoelectrics, 1994, Kansas City, Kansas, USA, 1994.

10. Kushch, A., Karri, M. A., Helenbrook, B. T. and Richter Clayton, J., "The Effects of an Exhaust Thermoelectric Generator of a GM Sierra Pickup Truck." Proceedings of Diesel Engine Emission Reduction (DEER) conference, 2004, Coronado, California, USA, 2004

11. Vining, C.B. "An inconvenient truth about thermoelectrics", Nature Materials, 8, February 2009;

12. Zhang, X., Zeng, K., Bai, S., Zhang, Y. et al., "Exhaust Recovery of Vehicle Gasoline Engine Based on Organic Rankine Cycle," SAE Technical Paper 2011-01-1339, 2011, doi:10.4271/2011-01-1339.

13. Hogan, T.P. et al, "Nanostructured Thermoelectric Materials and High-Efficiency Power-Generation Modules", Journal of Electronic Materials, Vol. 36, No. 7, 2007
14. Pei, Y., Shi, X., LaLonde, A., Wang, H., Chen, L., Snyder, J. "Convergence of electronic bands for high performance bulk thermoelectric", Nature, 473 (05 May 2011), pp. 66-69, 2011

15. Neild, A., "Portable Thermoelectric Generators," SAE Technical Paper $\underline{630019}$, 1963, doi: 10.4271/630019.

16. Birkholz, U., Grob, U. Stohrer and Voss, K., "Conversion of Waste Exhaust Heat in Automobile using FeSi2 Thermoelements". Proc. 7th International Conference on Thermoelectric Energy Conversion. 1988, Arlington, USA, pp. 124-128, 1988

17. Bass, J. C., Elsner, N. B. and Leavitt, F. A. "Performance of the $1 \mathrm{~kW}$ Thermoelectric Generator for Diesel Engines" International Conference on Thermoelectrics, 1994, Kansas City, Kansas, USA, 1994.

18. Kushch, A., Karri, M. A., Helenbrook, B. T. and Richter Clayton, J., "The Effects of an Exhaust Thermoelectric Generator of a GM Sierra Pickup Truck." Proceedings of Diesel Engine Emission Reduction (DEER) conference, 2004, Coronado, California, USA, 2004

19. LaGrandeur, J., Crane, D., Eder, A., "Vehicle Fuel Economy Improvement through Thermoelectric Waste Heat Recovery”, DEER Conference, 2005, Chicago, IL, USA, 2005

20. LaGrandeur, J., Crane, D., Hung, S., Mazar, B. and Eder, A., "Automotive waste heat conversion to electric power using skutterudite, TAGS, $\mathrm{PbTe}$ and BiTe", International conference on thermoelectric, p. 343-48, 2006

21. Thacher, E. F., Helenbrook, B. T., Karri, M. A., and Richter Clayton, J. "Testing an automobile thermoelectric exhaust based thermoelectric generator in a light truck" Proceedings of the I MECH E Part D Journal of Automobile Engineering, 221-1, pp. 95-107(13), 2007.

22. Stobart, R., Wijewardane, A., and Allen, C., "The Potential for Thermo-Electric Devices in Passenger Vehicle Applications," SAE Technical Paper 2010-01-0833, 2010, doi:10.4271/2010-01-0833.

23. Bell, L., "Cooling, heating, generating power, and recovering waste heat with thermoelectric systems", Science, 321, pp. 1457-1461, 2008.

24. Gao, Min and Rowe, D. M., "Conversion Efficiency of Thermoelectric Combustion Systems" IEEE Transactions on Energy Conversion, 22-2, June, 2007

25. Mori, M., Yamagami, T., Sorazawa, M., Miyabe, T. et al., "Simulation of Fuel Economy Effectiveness of Exhaust Heat Recovery System Using Thermoelectric Generator in a Series Hybrid," SAE Int. J. Mater. Manuf. 4(1):1268-1276, 2011, doi:10.4271/2011-01-1335.

26. Whitworth, B., "BMW reveals plans for Efficient Dynamics Mk2 - interview with BMW's head of development Klaus Draeger", in car Magazine, March 2009. link: http:// 
www.carmagazine.co.uk/News/Search-Results/IndustryNews/BMW-reveals-plans-for-Efficient-Dynamics-Mk2/

27. Matsubara, K., "Development of a high efficient thermoelectric stack for a waste exhaust heat recovery of vehicles", International conference on thermoelectric, p. 418-23, 2002.

28. Gonçalves, L.M., Martins, J., Antunes, J., Rocha, R. and, Brito, F. P. "Heat-Pipe Assisted Thermoelectric Generators for Exhaust Gas Applications", ASME 2010 International Mechanical Engineering Congress \& Exposition, November, 12-18, 2010, Vancouver, British Columbia, Canada, 2010.

29. Martins, J., Goncalves, L., Antunes, J., and Brito, F., "Thermoelectric Exhaust Energy Recovery with Temperature Control through Heat Pipes," SAE Technical Paper 2011-01-0315, 2011, doi:10.4271/2011-01-0315.

30. Brito, F.P., Martins, J., Goncalves, L.M., Sousa, R. "Modelling of Thermoelectric Generator with Heat Pipe Assist for Range Extender Application", 37th Annual Conference of the IEEE Industrial Electronics Society (IECON 2011), November 7-10th, Melbourne, Australia, 2011

31. Martins, J., Uzuneanu, K., Ribeiro, B., and Jasasky, O., "Thermodynamic Analysis of an Over-Expanded Engine," SAE Technical Paper 2004-01-0617, 2004, doi: 10.4271/2004-01-0617.

32. Goldsmid, H. J., "CRC Handbook of Thermoelectrics", London CRC Press, edited by Rowe, D.M., 1987.

\section{CONTACT INFORMATION}

Jorge Martins is an Associate Professor at the Mechanical Engineering Department of the Universidade do Minho at Guimaraes, Portugal, where he is head of the I.C. Engines Laboratory. He can be contacted at jmartins@dem.uminho.pt

Francisco P. Brito is a Post-Doctoral researcher at the Universidade do Minho at Guimaraes, Portugal and an Invited Assistant Professor at ISEP (Porto, Portugal). He can be contacted at francisco@dem.uminho.pt

Luís Gonçalves is an Auxiliar Professor at the Industrial Electronics Department of the Universidade do Minho at
Guimaraes, Portugal. He can be contacted at lgoncalves@dei.uminho.pt

\section{ACKNOWLEDGMENTS}

Francisco Brito thanks the FCT and the MIT Portugal Program for the financial support given for his research activities (SFRH / BPD / 51048 / 2010).

This research project was supported by MIT-Pt/EDAM-SMS/ 0030/2008.

\section{DEFINITIONS/ABBREVIATIONS}

\section{EREV}

Extended Range Electric Vehicle

HP

Heat Pipe

TEG

Thermoelectric Generator

VCHP

Variable Conductance Heat Pipe

ZT

Figure-of-merit of a thermoelectric module
The Engineering Meetings Board has approved this paper for publication. It has successfully completed SAE's peer review process under the supervision of the session organizer. This process requires a minimum of three (3) reviews by industry experts.

All rights reserved. No part of this publication may be reproduced, stored in a retrieval system, or transmitted, in any form or by any means, electronic, mechanical, photocopying, recording, or otherwise, without the prior written permission of SAE. ISSN 0148-7191
Positions and opinions advanced in this paper are those of the author(s) and not necessarily those of SAE. The author is solely responsible for the content of the paper.

SAE Customer Service:

Tel: 877-606-7323 (inside USA and Canada)

Tel: 724-776-4970 (outside USA)

Fax: 724-776-0790

Email: CustomerService@sae.org

SAE Web Address: http://www.sae.org

Printed in USA 